\title{
A short fuse after alcohol: implicit power associations predict aggressiveness after alcohol consumption in young heavy drinkers with limited executive control
}

Citation for published version (APA):

Wiers, R. W. H. J., Beckers, L., Houben, K. M. P. I., \& Hofmann, W. (2009). A short fuse after alcohol: implicit power associations predict aggressiveness after alcohol consumption in young heavy drinkers with limited executive control. Pharmacology, Biochemistry and Behavior, 93, 300-305. https://doi.org/10.1016/j.pbb.2009.02.003

Document status and date:

Published: 01/01/2009

DOI:

10.1016/j.pbb.2009.02.003

Document Version:

Publisher's PDF, also known as Version of record

Document license:

Taverne

Please check the document version of this publication:

- A submitted manuscript is the version of the article upon submission and before peer-review. There can be important differences between the submitted version and the official published version of record.

People interested in the research are advised to contact the author for the final version of the publication, or visit the DOI to the publisher's website.

- The final author version and the galley proof are versions of the publication after peer review.

- The final published version features the final layout of the paper including the volume, issue and page numbers.

Link to publication

\footnotetext{
General rights rights.

- You may freely distribute the URL identifying the publication in the public portal. please follow below link for the End User Agreement:

www.umlib.nl/taverne-license

Take down policy

If you believe that this document breaches copyright please contact us at:

repository@maastrichtuniversity.nl

providing details and we will investigate your claim.
}

Copyright and moral rights for the publications made accessible in the public portal are retained by the authors and/or other copyright owners and it is a condition of accessing publications that users recognise and abide by the legal requirements associated with these

- Users may download and print one copy of any publication from the public portal for the purpose of private study or research.

- You may not further distribute the material or use it for any profit-making activity or commercial gain

If the publication is distributed under the terms of Article 25fa of the Dutch Copyright Act, indicated by the "Taverne" license above, 


\title{
A short fuse after alcohol: Implicit power associations predict aggressiveness after alcohol consumption in young heavy drinkers with limited executive control
}

\author{
Reinout W. Wiers ${ }^{\mathrm{a}, *, 1}$, Leen Beckers ${ }^{\mathrm{b}}$, Katrijn Houben ${ }^{\mathrm{b}}$, Wilhelm Hofmann ${ }^{\mathrm{c}}$ \\ ${ }^{a}$ University of Amsterdam, The Netherlands \\ ${ }^{\mathrm{b}}$ Maastricht University, The Netherlands \\ ${ }^{\mathrm{c}}$ University of Würzburg, Germany
}

\section{A R T I C L E I N F O}

Available online 23 February 2009

\section{Keywords:}

Alcohol

Aggression

Dual-process

Implicit Association Test

Executive control

\begin{abstract}
A B S T R A C T
This study tested a hypothesis derived from recent dual-process models, which conceptualize behavior as the interplay of associative and Executive Control (EC) processes. This general logic was applied here to the phenomenon of aggressiveness after drinking alcohol. Specifically, we predicted that automatic associations between alcohol and power would predict aggressiveness after drinking in men with relatively weak EC. Participants were 57 heavy drinking male students, who completed two versions of the Implicit Association Test (IAT), one assessing alcohol-power associations (hypothesized critical associations) and one alcoholarousal associations (control-test), a classical Stroop test (measure of EC) and a number of alcohol-related questionnaires, including four questions on aggressiveness after drinking (dependent variable). As predicted, automatic alcohol-power associations significantly predicted self-reported aggressiveness after drinking in low but not in high EC individuals. As expected, this interaction was specific for alcohol-power associations since it was not found with regard to alcohol-arousal associations. We argue that this finding, together with a recent related findings, indicates that specific instances of "impulsivity" can be conceptualized as the joint outcome of two processes: a general weak EC and an associative process that predicts the impulsive behavior under study when not inhibited by EC processes.
\end{abstract}

(C) 2009 Elsevier Inc. All rights reserved.

\section{Introduction}

During the past years many dual-process models have been proposed to account for a variety of perplexing psychological phenomena, including common errors in human reasoning and decision making (Evans, 2003; Kahneman, 2003; Strack and Deutsch, 2004). Recently, varieties of these models have been developed to predict the etiology and maintenance of addictive behaviors (Bechara et al., 2006; Deutsch and Strack, 2006; Evans and Coventry, 2006; Stacy et al., 2004; Wiers et al., 2007; Wiers and Stacy, 2006). In these models, addictive behaviors are seen as the joint outcome of two types of processes: a fast, associative, impulsive process, which includes an automatic appraisal of stimuli in terms of their affective and motivational significance and a slower, rule-based, reflective process, which includes processes of deliberation and goal regulation according to expected outcomes (Deutsch and Strack, 2006; Evans and

\footnotetext{
* Corresponding author. Dept of Psychology, University of Amsterdam, Roetersstraa 15, 1018 WB Amsterdam, The Netherlands. Tel.: +3120525 6842; fax: +31206390279. E-mail address: R.Wiers@uva.nl (R.W.Wiers).

1 This research was conducted when the first author was still at the Faculty of Psychology, Maastricht University, The Netherlands. This research was funded by "VIDI" grant 452.02.005 from the Dutch National Science Foundation (N.W.O.) awarded to the first author. The authors wish to thank Tim Schoenmakers and Andrea Wolf for their help with the preparation of this manuscript.
}

Coventry, 2006; Strack and Deutsch, 2004; Wiers et al., 2007; Wiers et al., in press). Importantly, reflective but not impulsive processing is assumed to heavily depend on Executive Control (EC) functions in order to operate properly. Specifically, EC may be needed for the representation and maintenance of regulatory goals as well as for shielding these goals from impulsive interference. Consequently, under low EC, reflective processing breaks down and impulsive processes "take over". In line with these theories, recent studies found that implicit alcohol-associations are a better predictor of alcohol use in adolescents with relatively weak EC (Grenard et al., 2008; Houben and Wiers, 2009; Thush et al., 2008). Hence, relatively automatic associations are more important in the prediction of addictive behaviors as the self-regulatory influence of EC wanes. There is also emerging evidence that EC decrease as a long-term consequence of addictive behaviors, especially when this takes place during adolescence (Wiers et al., 2007). This may make the addicted individual even more vulnerable to the influence of impulsive processing on (addictive) behavior. Finally, there is evidence demonstrating that acute alcohol consumption specifically impairs EC but not associative processing (Fillmore and Vogel-Sprott, 2006). This acute alcohol effect can also shift the balance between reflective and impulsive processing: for example, after an acute dose of alcohol, automatic (implicit) attitudes toward sweets predicted sweet-consumption more strongly than when no alcohol was given (Hofmann and Friese, 2008). Again, 
this effect may be due to an impairment of EC due to alcohol, resulting in a stronger effect of automatic processing on behavior.

The purpose of the present study was to combine the above theorizing on EC as a key moderator of impulsive/reflective processing with the known disinhibiting effects of alcohol on behavior. Specifically, the alcohol-related behavior we focused on in the present study is aggression after drinking alcohol. There is a large literature documenting increased aggression after alcohol, especially in men (Giancola, 2002). From the perspective of dual-process models, this effect may be most likely due to a stronger impact of impulsive processing on behavior. From our dual process perspective, the question then becomes which associative process leads to aggressiveness after alcohol, when not moderated by EC processes. We hypothesized that a particularly relevant impulsive process for aggression under influence of alcohol would be automatically activated associations between alcohol and power. This hypothesis was derived from two sources. First, early research on alcohol expectancies found that expectancies of power and aggression are strongly correlated (e.g., (Brown et al., 1987, 1980), and power motivation and feelings of masculinity were found to increase in men after drinking alcohol (McClelland, 1974). Second, a recent evolutionary account of addiction places self-perceived fitness ("SPFit") at the core of addiction (Newlin, 2002). According to this SPFit theory, the cortico-mesolimbic dopamine system is a basic motivational system crucial for survival and reproduction, which can be activated by perceived threats to survival and opportunities for reproduction. According to SPFit theory, drugs of abuse artificially inflate feelings of personal power and sexual attractiveness (Newlin, 2002, p. 249). The same activation may also lead to a more aggressive reaction to threats (ibid, p. 433). Note that SPFit-theory predicts that acute effects are enhanced subjective feelings of power and sexual attractiveness, which may not match the impression of objective bystanders (Newlin, 2002). Hence, based on SPFit and earlier work using implicit (McClelland) and explicit (expectancy) measures suggest that alcohol-power associations would be predictive of aggression under influence of alcohol. In order to investigate specificity of this prediction, we also included a measure of implicit alcohol-arousal associations, which we previously found to be predictive of heavy drinking, even after controlling for explicit measures of alcohol expectancies (Wiers et al., 2006, 2007), but for which we have no reason to expect an association with aggressiveness after alcohol. In summary, we assessed two measures of automatic alcohol-associations, one assessing alcohol-power associations, and one alcohol-arousal associations, and we predict that only alcoholpower associations are related to aggressiveness after drinking alcohol.

In line with our general theorizing (Grenard et al., 2008; Hofmann et al., 2008; Houben and Wiers, 2009; Thush et al., 2008), the influence of alcohol-power associations on behavior is expected to be conditional: we hypothesized that the influence of impulsive processes on actual behavior hinges crucially on whether an individual has sufficient EC at his or her disposal in order to inhibit or override the behavioral implications of the impulse. There is growing evidence that EC may play an important role in the alcoholaggression relationship (Giancola, 2000, 2002, 2004). Hence, from our dual-process model, we predict that relatively weak EC will only lead to aggression after alcohol in individuals with strong alcohol-power associations. For instance, a person harboring strong alcohol-power associations may nevertheless refrain from acting aggressively provided he or she is able to recruit sufficient executive control to withhold or regulate the impulse. Similarly, a person with weak EC is not expected to show aggression after drinking alcohol in the absence of strong alcohol-power associations. In summary, we hypothesized that relationship between alcohol-power associations and aggressiveness following alcohol use is moderated by EC, such that it is only found in men with relatively weak EC.
In order to assess alcohol-power and alcohol-arousal associations, we employed two variants of the Implicit Association Test (IAT) (Greenwald et al., 1998). This is a reliable reaction-time (RT) test to assess memory associations, which has been used in alcohol-research to predict alcohol use and problems (De Houwer et al., 2004; Houben and Wiers, 2006; Thush and Wiers, 2007; Wiers et al., 2002). EC were assessed with the well known color-interference Stroop test, a well validated test of EC, and self-regulatory capacity, which activates prefrontal and cingulated cortices (Carter and Van der Veen, 2007; Marsh et al., 2006; McClelland, 1974; Mitchell, 2005). While our first studies on moderation of automatic impulses used measures of individual differences in working memory as index of the moderating influence of EC (Grenard et al., 2008; Hofmann et al., 2008; Thush et al., 2008), in a recent study we found a similar pattern of moderation using the classical Stroop as moderator (Houben and Wiers, 2009).

\section{Method}

\subsection{Participants}

Fifty-seven heavy drinking male students from Maastricht University, between 17 and 30 years of age ( $M=21.07$ years; $S D=2.65)$, participated in exchange for course credit or a gift certificate. Interested students e-mailed their telephone number and were telephone-screened with a brief interview including their alcohol consumption during each of the past 7 days. Inclusion criteria were male gender, weekly alcohol consumption above the median (15 drinks) for male students in The Netherlands, including at least one binge (more than 5 drinks on one occasion) during the past 2 weeks. All participants scored above the cut-off ( 8 ) for hazardous drinking on the Alcohol Use Disorder Identification Test (AUDIT) (Saunders et al., 1993). Mean AUDIT score in this sample was $13.65(S D=.51)$, for which 11 has been proposed as a cut-off for a likely alcohol problem in students (Fleming et al., 1991).

\subsection{Materials and measures}

\subsubsection{Implicit Association Tests}

Participants performed two IATs (Greenwald et al., 1998): one aimed at assessing associations between alcohol and power (PowerIAT) and one assessing associations between alcohol and arousal (Arousal-IAT). The IAT is a speeded categorization task in which participants classify stimuli (words or pictures, in the versions used here only words) into two times two categories, using two response keys. In both IATs, one categorization concerned beers vs. softdrinks, with stimuli being six well known beer-brands (e.g. "Heineken") and six well-known softdrink brands (e.g. "Pepsi"). In the Power-IAT, the other categorization concerned the categories Powerful (stimuli: forceful, dominant, strong, win) vs. Weak (stimuli: defenseless, helpless, feeble, and lost). In the Arousal-IAT, the other categorization concerned "Active" (stimuli: energetic, lively, cheerful, and loose) vs. "Passive" (stimuli: sleepy, listless, sick, and drowsy). The opposing categories were matched on number of syllables (in Dutch).

In the IAT, both categorizations are first practiced separately. For example, in the Power-IAT, first participants practice to quickly categorize stimuli appearing in the center of the screen (here brand names) into the "Beer" or "Soft-drink" categories, by pressing with their left or right index-finger (response-assignments were counterbalanced). They then practice the other categorization, here Powerful vs. Weak, using the same response keys. In the first critical combination block, these two practiced combinations are combined, hence, when stimuli refer to either "Beer" or "Powerful", they press the one key, when they refer to "Softdrinks" or "Weak", they press the other. In the next phase, the single categorization of attributes was practiced with opposite response assignments (i.e. switch of side for Powerful vs. 
Table 1

Overview IAT procedure for alcohol-power and alcohol-arousal associations.

\begin{tabular}{|c|c|c|c|c|c|}
\hline & Target concept discrimination & Attribute discrimination & Combination task & Reversed attribute discrimination & Reversed combination task \\
\hline \multicolumn{6}{|l|}{ Power } \\
\hline Key 1 & Beer & Powerful & Beer or Powerful & Weak & Beer or Weak \\
\hline Key 2 & Softdrinks & Weak & Softdrinks or Weak & Powerful & Softdrinks or Powerful \\
\hline \multicolumn{6}{|l|}{ Arousal } \\
\hline Key 1 & Beer & Active & Beer or Active & Passive & Beer or Passive \\
\hline Key 2 & Softdrinks & Passive & Softdrinks or Passive & Active & Softdrinks or Active \\
\hline
\end{tabular}

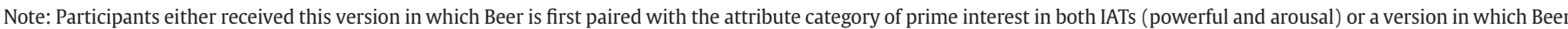

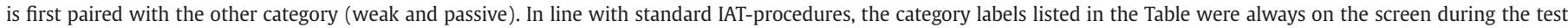
(in phase one \{target concept discrimination\} only "Beer" and "Softdrink", in the combination phases always two concepts on each side.

Weak). This reverse assignment received a double practice dose, which makes the IAT-effect less sensitive to order-effects (Nosek et al., 2005). After this the other critical combination task was assessed, now combining "Beer" with "Weak" and "Softdrinks" with "Powerful". The IAT effect is calculated as the difference in (log-transformed) reaction times between the two combined categorizations. The underlying assumption is that when two categories are more strongly associated in memory, responses are faster when they share the same response-key. Hence, we expected that the "Beer" with "Powerful" (and "Softdrink" with "Weak") combination would be performed faster on average by the heavy drinking participants than the opposite categorization (BeerWeak and Softdrink-Powerful). Half of the participants first did the BeerPowerful categorization and then the Beer-Weak categorization (as in the example) and the other half did the task in the opposite order.

The Arousal-IAT was congruent with the Power-IAT and with earlier work with this task (Wiers et al., 2002, 2005). Based on this earlier work we expected that the heavy drinkers would be faster to categorize alcohol and active together (and softdrink with passive) than the opposite assignment (alcohol-passive vs. softdrink-active). Participants received the same version for these two IATs: if they received the Power-IAT in which Beer and Powerful were first categorized together, they also received the Arousal-IAT in which Beer and Active were first categorized together. When they first received the Beer-Weak categorization in the Power-IAT, they also first received the Beer-Passive categorization in the Arousal-IAT (see Table 1 for an overview of the IAT procedures).

During both versions of the IAT, target and attribute stimuli were presented in the middle of the computer screen, in black 14 point font. Further, the labels of the categories assigned to the left and right response key were presented in the corresponding upper corners of the computer screen. Stimuli remained on screen until a response was given. The inter-trial interval was $250 \mathrm{~ms}$. Feedback was presented in red beneath the stimuli after an incorrect response ('wrong'), and when responses were too fast $(<300 \mathrm{~ms}$; 'too fast') or too slow (>3000 ms; 'too slow').

\subsubsection{Trait aggression}

Trait aggression was assessed with the Buss-Perry aggression scale (Buss and Perry, 1992). The scale consists of 29 items covering four facets of aggression, physical aggression, verbal aggression, anger, and hostility, which are answered on a 5-point Likert scale. Reliability of the total scale was good $(\alpha=.86)$. A higher score indicates a higher level of trait aggression.

\subsubsection{Executive control: classical Stroop task}

The Stroop-interference test started with a practice phase in which ink-color to key assignment was practiced with sixteen trials in which meaningless letter strings (e.g. \#\#\#\#\#) were presented in one of four colors (red, blue, yellow, and green). Participants responded with a key press on a response pad to which colored stickers had been added as a reminder of the color-key assignment. After the practice phase, participants completed 48 test trials of which 24 were congruent (e.g. the word "yellow" in yellow ink) and 24 incongruent (e.g. the word "blue" in yellow ink, correct response is yellow), all presented in the middle of the screen in 18 point font.

\subsubsection{Aggressiveness under alcohol Influence}

The dependent variable in this study was self-reported aggressiveness after drinking alcohol. This variable was calculated from four items ( $\alpha=.63)$, which were part of a scale of expected outcomes of alcohol use (hidden between other items). All items started with the stem "After drinking alcohol I feel", followed by an adjective. The four items were: aggressive; cheeky; hot-tempered; annoyed. Other alcohol-expectancy scales were: active, passive, powerful, weak, and excited, and they used the same words as used in the powerful-weak and the active-passive IATs (Wiers et al., 2002, 2005). The expectancies were scored on a 7-point Likert scale with scores ranging from never (0) to always (6).

\subsubsection{Alcohol and drug use}

Alcohol and drug use were assessed with a questionnaire in for a number of licit and illicit substances both lifetime and use during the past month was asked (Van den Wildenberg et al., 2007).

\subsubsection{Alcohol problems}

Alcohol problems were assessed with the World Health Organization's Alcohol Use Disorders Identification Test (AUDIT). The questionnaire consists of ten items and is used to identify persons whose alcohol consumption patterns may put them at risk for alcohol-related harm (Saunders et al., 1993).

\subsection{Procedure}

Participants first performed the alcohol-power IAT, followed by the classical Stroop task and the alcohol-arousal IAT. After this they filled out the questionnaires; first the alcohol expectancies (including the four alcohol-aggression items), followed by the questionnaires on alcohol and drug use and the measure of trait aggression. The research protocol was ethically approved by the Institutional Review Board (ethical committee psychology). At the end of the experiment, participants were thanked for their cooperation, received a gift certificate (€7.5, approximately $12 \$$ ), and were provided with debriefing information.

\subsection{Analysis}

\subsubsection{Preliminary analyses}

IAT effects were calculated with the D600 scoring algorithm (Greenwald et al., 2003). Following the formula presented by Greenwald et al., practice blocks were included, error penalties (600 ms) were given, and results were standardized at the level of the participant. For both IATs, the D600 measure was calculated so that higher scores indicate faster performance for the compatible response assignment (i.e., 'beer' + 'powerful' or 'active' vs. 'softdrinks' + 'weak'/ 'passive') than for the incompatible response assignment (i.e., 'beer' + 'weak'/'passive' vs. 'softdrinks' + 'powerful' or 'active'). 
Preparatory analyses revealed no influential outliers on IAT data. With respect to the estimate of executive control from the classical Stroop, we calculated mean log-transformed response latencies of the Stroop task separately for the congruent test trials and for the incongruent test trials. Next, a measure of response inhibition was calculated by subtracting the average log-transformed response latencies during the congruent trials from the average log-transformed response latencies during the incompatible trials.

\subsubsection{Moderation analyses}

Moderation analyses were performed following the guidelines of Cohen et al. (2003). We performed a series of multiple regression analyses. The dependent variable was the self-reported aggressiveness after drinking alcohol. As predictors, we entered implicit beerpower associations (IAT), trait aggression, response inhibition (Stroop), and the interactions between response inhibition and beer-power associations and the interaction between response inhibition and trait aggression. All predictor variables were centered and interaction terms were computed from these centered scores (Cohen et al., 2003). The crucial interaction between Executive Control and Implicit Power Associations was analyzed with simple slope analyses, and depicted by plotting the prediction of aggression after alcohol for participants with low ( -1 SD) and high (+1 SD) automatic implicit alcohol-power associations (assessed with an IAT) depending on low ( $-1 \mathrm{SD}$ ) and high (+1 SD) executive control as assessed with a Stroop task (Cohen et al., 2003).

\section{Results}

\subsection{Preliminary analyses}

The beer-power IAT yielded a significant IAT-effect, $t(56)=7.50$, $p<.001$, indicating that participants were faster when "beer" shared the response key with the "powerful" attribute category than when "beer" was paired with the "weak" attribute category. The beerarousal IAT yielded an effect in the expected direction which did not reach statistical significance $(t(56)=1.68, p<.10)$, indicating that participants tended to be faster to categorize beer with active than with passive words.

Results showed a significant Stroop effect, $t(56)=8.06, p<.001$, which indicates that participants were faster in naming the colors in which words were presented during the congruent trials compared to the incongruent trials. Higher scores on this Stroop-index indicate stronger interference or weaker EC. No influential outliers were found on this measure.

\subsection{Moderator analysis}

The multiple regression analysis on the prediction of aggressiveness after drinking alcohol was significant, $R^{2}=.22, F(5,51)=2.84, p=.024$. There were two significant predictors: trait aggression $(\beta=.32$, $p=.015)$ and the interaction between beer-power associations and Stroop interference $(\beta=.31, p=.019)$. All other predictors were not significant ( $p$-values $>19$ ). Note that both signs are in the expected direction: high scores on trait-aggression are associated with higher aggressiveness after alcohol consumption and the interaction term indicates a stronger relationship between beer-power associations and aggressiveness after drinking alcohol for individuals with strong Stroop interference score, hence with low executive control. This interaction is depicted in Fig. 1. Simple slope analyses (Cohen et al., 2003) confirmed that the prediction of aggressiveness after alcohol consumption by beerpower associations was significant for individuals with high Stroopinterference (i.e., low EC), $\beta=.49, p=.020$, but not for individuals with low Stroop-interference (i.e., good EC), $\beta=-.13, p=.45$.

In order to test the specificity of the moderated prediction of the beer-power associations in the prediction of aggressiveness after

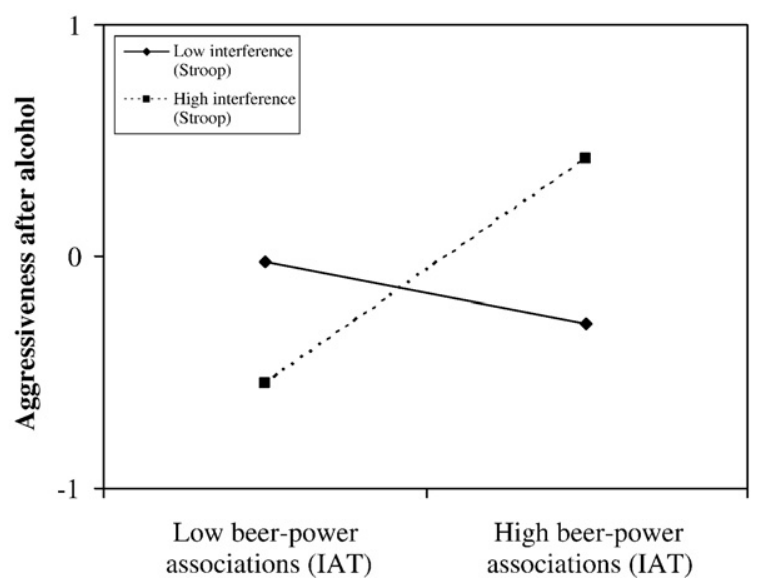

Fig. 1. Moderator effect of executive control on the relationship between implicit alcoholpower associations and self-reported aggressiveness after alcohol consumption. The graph shows the predicted aggressiveness for participants with low ( $-1 \mathrm{SD})$ and high (+1 SD) automatic implicit alcohol-power associations (assessed with an IAT) depending on low $(-1 \mathrm{SD})$ and high $(+1 \mathrm{SD})$ executive control as assessed with a Stroop task.

alcohol, we performed an identical moderated regression analysis, substituting the beer-power IAT measure by the beer-arousal measure (both as a main effect and in interaction with the measure of response inhibition). In this control analysis, the interaction between beerarousal associations and response inhibition was not a significant predictor of aggressiveness after drinking alcohol $(p=.26)$ confirming the specificity of the beer-power associations in the prediction of aggressiveness after drinking alcohol in participants scoring relatively weak response inhibition. We further tested whether the moderated prediction of alcohol-power associations of aggressiveness after drinking was still found after controlling for a measure of alcohol use and problems (AUDIT), and this was the case (same pattern of results, AUDIT score was not a significant predictor, $p>.50$ ).

\section{Discussion}

Based on recent dual-process models regarding the interplay between impulsive associative and Executive Control (EC) processes, the present study tested whether automatic associations between alcohol and power predicted aggressiveness after drinking alcohol in men with relatively weak EC as assessed with a classical Stroop test. This hypothesis was confirmed. Further, the moderated prediction was specific: alcohol-arousal associations did not predict aggressiveness after drinking in low EC individuals. Together with a number of converging recent findings (Grenard et al., 2008; Hofmann et al., 2008; Houben and Wiers, 2009; Thush et al., 2008), these results indicate that both associative processes and EC are crucial when one investigates the role of "impulsivity" in relation to addictive behaviors and other behaviors performed under the influence of alcohol or drugs. We argue that "impulsivity" can be conceptualized as the joint outcome of two different types of processes: an associative process and an EC process. In case of addictive behaviors, the associative process is usually appetitive in nature, leading to an action tendency to approach the substance. This approach tendency can lead to the appetitive behavior in question, but when there is motivation and ability to control this appetitive impulse, this impulse can be inhibited (Hofmann et al.,2008b; Wiers et al., 2007). Recent studies have empirically confirmed this notion: memory associations strongly predicted subsequent alcohol use in adolescents with low working memory capacity, but not in adolescents with high working memory capacity (Grenard et al., 2008; Thush et al., 2008), with similar findings for smoking (Grenard et al., 2008). Recently, similar moderation was found for the EC measure used here (classical Stroop 
interference scores), with implicit alcohol associations predicting alcohol use in individuals with relatively weak EC (large Stroop interference), but not in individuals with relatively good EC (weak Stroop interference) (Houben and Wiers, 2009). Importantly, in all of these studies, measures of EC, did not predict the addictive behavior as main effects, but only in interaction with the relevant associative process, as is the case here. One may wonder to what extent different executive functions have the same or unique moderating roles in the inhibition of associative impulses. A recent study in the domain of impulsive eating indicated that different executive functions (working memory, inhibitory control and affect regulation) all show unique moderating effects (Hofmann et al., 2009a). More research regarding this issue in the domain of alcohol and aggression is needed.

There is a long tradition in addiction research linking impulsivity and related constructs (e.g. behavioral undercontrol, (Sher, 1991)) to risk for later addiction (Jentsch and Taylor, 1999; Verdejo-Garcia et al., 2008). From our perspective it may be useful to distinguish between a general capacity to control one's impulses and the more domainspecific impulsive processes one may develop. Hence, we argue that there is more to impulsivity than just a general lack of executive control: there also needs to be an associative process that leads to that behavior in question, when not controlled. In the development of addictive behaviors, there is evidence that a number of more or less automatic appetitive processes fulfill this role: after prolonged substance use, the substance captures attention (attentional bias) and elicits approach tendencies (see (Wiers et al., 2007) for a review). There is also emerging evidence that these processes can be cued by a prime-dose of the substance (Field et al., 2008; Schoenmakers et al., 2008). To sum up, from our perspective, an individual can be impulsive in the sense that (s)he has a general limited capacity for self-control and self-regulation, but to predict a specific impulsive behavior (aggression, unsafe sex, alcohol or drug use), it is necessary to also assess the impulsive process that leads to the behavior in question: in the absence of activation of the relevant associations, the impulsive behavior is not observed in individuals with low capacity for self-regulation (cf. Hofmann et al., 2008).

In the present study we applied the same dual-process logic to the phenomenon of aggression after alcohol consumption. Although there is a substantial literature linking relatively weak executive control processes to increased aggression after drinking alcohol, especially in men (e.g. (Giancola, 2000, 2002, 2004)), we argue that there must also be an associative process at play which steers toward aggression, when EC is impaired; a well-documented acute alcohol effect, (Fillmore and Vogel-Sprott, 2006). Based on a recent evolutionary account of addiction (Newlin, 2002) and earlier work on alcoholrelated cognitive motivational processes, we predicted that automatic associations between alcohol and power would be a prime-candidate. When these associations are strong, any threat to the feeling of subjective fitness is likely to be retaliated with aggression (Newlin, 2002). The results of the present study confirm this hypothesis. Note that not all individuals with relatively weak EC report aggression after drinking alcohol, only those with strong automatic associations between alcohol and power. Hence, the combination of a strong associative process and relatively weak EC appears to be crucial for the prediction of aggression after drinking alcohol.

Although the present findings are interesting and in line with recent dual-process models, some limitations should be acknowledged. First, the behavior central in this study, aggressiveness after drinking alcohol, was assessed with a self-report scale only, which had a moderate reliability. We tried to obtain additional information from collaterals ( $a$ friend rating the usual behavior of the participant after drinking alcohol) but this resulted in data for less than half of the participants and could therefore not be used. It should be noted that the behavior central in this study was hidden in a long questionnaire concerning expected behavior after drinking alcohol (4 out of 34 questions). Further, in a recent study, a similar moderation effect was found on actual aggressive behavior (Hofmann et al., 2008; Study 3). In that study, the association between the self and angry traits (i.e., the automatic angriness self-concept) was assessed with an IAT, and EC with a measure of working memory. Two weeks later, participants took part in a social perception task, in which their own performance on the working memory task was judged negatively by a same-sex interaction partner in an anger provoking way. After this they were given the opportunity to retaliate by means of giving feedback about this person's performance. Results indicated that only low EC individuals with high self-aggression associations retaliated. Hence, a similar pattern of results was found as in the present study, despite these differences in all critical aspects of the methods used (different measure of the associative process, different measure of EC, different dependent variable). Despite this converging evidence, it would be good to replicate the present findings with a behavioral measure of aggression after alcohol as dependent variable. A second limitation of the present study was that the two IATs were not counterbalanced. This procedural decision was driven by our intention to assess the associations of primary interest (alcohol-power) first, and the control measure (alcohol-arousal associations), second. It is possible that our finding regarding the specificity of alcohol-power associations (vs. alcohol-arousal associations) in the prediction of aggressiveness after alcohol was influenced by this procedural decision. Although we previously did not find that predictive power of different IATs were reduced as a function of test order (Houben and Wiers, 2006; Wiers et al., 2005), it is noteworthy that both IATs here did not significantly predict the index of alcohol use and problems ( $p$-values>.50), although we have found previously that alcohol-arousal associations are predictive of heavy drinking (Houben and Wiers, 2006; Wiers et al., 2002). This may have been due to restriction of range (only heavy drinkers included). In any case, it would be interesting if a replication counterbalanced the assessment of alcohol-power and control associations. Third, we did not include a questionnaire measure of impulsivity here. It would be interesting for future research, to compare self-reported impulsivity scores with the combination of low EC and strong alcohol-power associations as predictors of aggressive tendencies after alcohol. Fourth, the present study assessed only men, for whom aggression after alcohol is more prevalent. However, future studies could study aggressiveness after alcohol in women as well from the present perspective.

The findings in this study lead to a number of follow-up questions, in addition to those directly following from the limitations. First, it would be interesting to test whether neural correlates of the EC processes (Ridderinkhof et al., 2004) and the associative processes (van de Laar et al., 2004) involved could be outlined directly in the context of self-regulatory conflicts in addictive behaviors. Second, in view of the enormous societal impact of aggression after drinking alcohol, future studies could investigate how both interacting predictors (low EC and strong alcohol-power associations) could be influenced to prevent "a short fuse after alcohol" (Wiers et al., in press). In conclusion, impulsive aggression after drinking alcohol appears to be predicted by the combination of automatically activated associations between alcohol and power in men relatively low in EC.

\section{References}

Bechara A, Noel X, Crone EA. Loss of willpower: abnormal neural mechanisms of impulse control and decision making in addiction. In: Wiers RW, Stacy AW, editors. Handbook of Implicit Cognition and Addiction. Thousand Oaks, CA: SAGE Publishers; 2006. p. 215-32.

Brown SA, Goldman MS, Inn A, Anderson L. Expectations of reinforcement from alcohol: their domain and relation to drinking patterns. J Consult Clin Psychol 1980;48.

Brown SA, Christiansen BA, Goldman MS. The alcohol expectancy questionnaire: an instrument for the assessment of adolescent and adult alcohol expectancies. J Stud Alcohol 1987;48:483-91.

Buss AH, Perry M. The aggression questionnaire. J Pers Soc Psychol 1992;63:452-9.

Carter CS, Van der Veen V. Anterior cingulate cortex and conflict detection: an update of theory and data. Cogn Affect Behav Neurosci 2007;7:367-79. 
Cohen, J., Cohen, P., West, S.G., Aiken, L.S. (2003) Applied multiple regression/ correlation analysis for the behavioral sciences. Lawrence Erlbaum Associates, Lawrence Erlbaum Associates.

De Houwer J, Crombez G, Koster EHW, De Beul N. Implicit alcohol-related cognitions in a clinical sample of heavy drinkers. J Behav Ther Exp Psychiatry 2004;35:275-86.

Deutsch R, Strack F. Reflective and impulsive determinants of addictive behavior. In: Wiers RW, Stacy AW, editors. Handbook of Implicit Cognition and Addiction. Thousand Oaks, CA: SAGE Publishers; 2006. p. 45-57.

Evans JSBT. In two minds: dual-process accounts of reasoning. Trends Cogn Sci 2003;7:454-9.

Evans JSBT, Coventry K. A dual process approach to behavioural addiction: the case of gambling. In: Wiers RW, Stacy AW, editors. Handbook of Implicit Cognition and Addiction. Thousand Oaks, CA: SAGE Publishers; 2006. p. 29-43.

Field M, Schoenmakers T, Wiers RW. Cognitive processes in alcohol binges: a review and research agenda. Current Drug Abuse Reviews 2008;1:263-79.

Fillmore MT, Vogel-Sprott M. Acute effects of alcohol and other drugs on automatic and intentional control. In: Wiers RW, Stacy AW, editors. Handbook on Implici Cognition and Addiction. Thousand Oaks, CA: SAGE Publishers; 2006. p. 293-306.

Fleming MF, Barry KL, MacDonald R. The alcohol use disorders identification test (AUDIT) in a college sample. Int J Addict 1991;26:1173-85.

Giancola PR. Executive functioning: a conceptual framework for alcohol-related aggression. Exp Clin Psychopharmacol 2000;8:576-97.

Giancola PR. The influence of trait anger on the alcohol-aggression relation in men and women. Neurobiological, behavioral and environmental relations to drinking. Alcohol Clin Exp Res 2002;26:1350-8.

Giancola PR. Executive functioning and alcohol-related aggression. J Abnorm Psychology 2004; $113: 541-55$

Greenwald AG, McGhee DE, Schwartz JLK. Measuring individual differences in implicit cognition: the Implicit Association Test. J Pers Soc Psychol 1998;74:1464-80.

Greenwald AG, Nosek BA, Banaji MR. Understanding and using the Implicit Association Test: I. An improved scoring algorithm. J Pers Soc Psychol 2003;85:197-216.

Grenard JL, Ames SL, Wiers RW, Thush C, Sussman S, Stacy AW. Working memory capacity moderates the predictive effects of drug-related associations on substance use. Psychol Addict Behav 2008;22:426-32.

Hofmann W, Friese M. Impulses got the better of me: alcohol moderates the influence of implicit attitudes toward food cues on eating behavior. J Abnorm Psychology 2008;117:420-7.

Hofmann W, Gschwendner T, Friese M, Wiers RW, Schmitt M. Working memory capacity and self-regulatory behavior: toward an individual differences perspective on behavior determination by automatic versus controlled processes. J Pers Soc Psychol 2008;95:962-77.

Hofmann W, Friese M, Roefs A. Three ways to resist temptation: The independent contributions of executive attention, inhibitory control, and affect regulation to the impulse control of eating behavior. Journal of Experimental Social Psychology 2009a;45:431-5.

Hofmann W, Friese M, Wiers RW. Impulsive versus Reflective Influences on Health Behavior: A Theoretical Framework and Empirical Review. Health Psychology Review 2008b;2:111-37.

Houben K, Wiers RW. Assessing implicit alcohol associations with the Implicit Association Test: fact or artifact? Addict Behav 2006;31:1346-62

Houben K, Wiers RW. Response Inhibition Moderates the Relationship between Implicit Associations and Drinking Behavior. Alcoholism: Clinical and Experimental Research 2009;33:626-33.

Jentsch JD, Taylor JR. Impulsivity resulting from frontostriatal dysfunction in drug abuse: implications for the control of behavior by reward-related stimuli. Psychopharmacology 1999;146:373-90.

Kahneman D. A perspective on judgment and choice: mapping bounded rationality. Am Psychol 2003;58:697-720.
Marsh R, Zhu H, Schultz RT, Quackenbush G, Royal J, Skudlarski P, et al. A developmental fMRI study of self-regulatory control. Hum Brain Mapp 2006;27:848-63.

McClelland D. Proceedings: drinking as a response to power needs in man. Psychopharmacol Bull 1974;10:5-6.

Mitchell R. The BOLD response during Stroop task-like inhibition paradigms: effects of task difficulty \& task-relevant modality. Brain Cogn 2005;59:23-37.

Newlin DB. The self-perceived survival ability and reproductive fitness (SPFit) theory of substance use disorders. Addiction 2002;97:427-45.

Nosek BA, Greenwald AG, Banaji MR. Understanding and using the Implicit Association Test: II. Method variables and construct validity. Pers Soc Psychol Bull 2005;31:166-80.

Ridderinkhof KR, Ullsperger M, Crone EA, Nieuwenhuis S. The role of the medial frontal cortex in cognitive control. Science 2004;306:443-7.

Saunders JB, Aasland OG, Babor TF, De la Fuente JR, Grant M. Development of the Alcohol Use Disorders Identification Test (AUDIT): WHO collaborative project on early detection of persons with harmful alcohol consumption. Addiction 1993:88:791-804.

Schoenmakers T, Wiers RW, Field M. Effects of a low dose of alcohol on cognitive biases and craving in heavy drinkers. Psychopharmacology 2008;197:169-78.

Sher KJ. Children of alcoholics, a critical appraisal of theory and research. University of Chicago Press; 1991.

Stacy AW, Ames SL, Knowlton B. Neurologically plausible distinctions in cognition relevant to drug use etiology and prevention. Subst Use Misuse 2004;39:1571-623.

Strack F, Deutsch R. Reflective and impulsive determinants of social behavior. Pers Soc Psychol Rev 2004;8:220-47.

Thush C, Wiers RW. Explicit and implicit alcohol-related cognitions and the prediction of current and future drinking in adolescents. Addict Behav 2007;32:1367-83.

Thush C, Wiers RW, Ames SL, Grenard JL, Sussman S, Stacy AW. Interactions between implicit and explicit cognition and working memory capacity in the prediction of alcohol use in at-risk adolescents. Drug Alcohol Depend 2008;94:116-24.

van de Laar MC, Licht R, Franken IH, Hendriks VM. Event-related potentials indicate motivational relevance of cocaine cues in abstinent cocaine addicts. Psychopharmacology (Berl) 2004;177:121-9.

Van den Wildenberg E, Wiers RW, Janssen RGJH, Lambrichs EH, Smeets HJM, Van Breukelen GJP. A functional polymorphism of the mu-opioid receptor gene (OPRM1) influences cue-induced craving for alcohol in male heavy drinkers. Alcohol Clin Exp Res 2007;31:1-10.

Verdejo-Garcia A Lawrence AJ, Clark L Impulsivity as a vulnerability marker for substance-use disorders: review of findings from high-risk research, problem gamblers and genetic association studies. Neurosci Biobehav Rev 2008;32:777-810.

Wiers RW, Stacy AW. Implicit cognition and addiction. Curr Dir Psychol Sci 2006;15:292-6.

Wiers RW, Van Woerden N, Smulders FTY, De Jong PJ. Implicit and explicit alcoholrelated cognitions in heavy and light drinkers. J Abnorm Psychol 2002;111:648-58.

Wiers RW, Van de Luitgaarden J, Van den Wildenberg E, Smulders FTY. Challenging implicit and explicit alcohol-related cognitions in young heavy drinkers. Addiction 2005;100:806-19.

Wiers RW, Houben K, Smulders FTY, Conrod PJ, Jones BT. To drink or not to drink: The role of automatic and controlled cognitive processes in the etiology of alcoholrelated problems. In: W. WR, Stacy AW, editors. Handbook of implicit cognition and addiction. Thousand Oaks, CA: SAGE Publishers; 2006. p. 339-61.

Wiers RW, Bartholow BD, Van den Wildenberg E, Thush C, Engels RCME, Sher KJ, et al. Automatic and controlled processes and the development of Addictive Behavior in adolescents: a review and a model. Pharmacol Biochem Behav 2007;86:263-83.

Wiers, R.W., Schoenmakers, T., Houben, K., Thush, C., Fadardi, J.S., Cox, W.M. (in press) Can problematic alcohol use be trained away? New behavioural treatments aimed at changing and moderating implicit cognitive processes in alcohol abuse. In: Martin CR (ed) Identification and treatment of alcohol dependency. M\&K Publishing, Keswick, UK. 